\title{
Long-term stability of maxillary anterior alignment in non-extraction cases
}

\author{
Luiz Filiphe Gonçalves Canuto ${ }^{1}$, Marcos Roberto de Freitas², Karina Maria Salvatore de Freitas ${ }^{3}$, \\ Rodrigo Hermont Cançado ${ }^{4}$, Leniana Santos Neves ${ }^{5}$
}

Objective: The purpose of this retrospective study was to evaluate long-term stability of maxillary incisors alignment in cases submitted to non-extraction orthodontic treatment. Methods: The sample comprised 23 patients (13 female; 10 male) at a mean initial age of 13.36 years $(\mathrm{SD}=1.81$ years), treated with fixed appliances. Dental cast measurements were obtained at three different time points $\left(\mathrm{T}_{1}\right.$ - pretreatment, $\mathrm{T}_{2}$ - posttreatment and $\mathrm{T}_{3}$ - long-term posttreatment). Variables assessed in maxillary arch were Little Irregularity Index, intercanine, interpremolar and intermolar widths, arch length and perimeter. The statistical analysis was performed by one-way ANOVA and Tukey tests when necessary. Pearson' correlation coefficients were used to investigate possible associations between the evaluated variables. Results: There was no significant change in most arch dimension measurements during and after treatment, however, during the long-term posttreatment period, it was observed a significant maxillary incisors crowding relapse. Conclusion: The maxillary incisors irregularity increased significantly $(1.52 \mathrm{~mm})$ during long-term posttreatment. None of the studied clinical factors demonstrated to be predictive of the maxillary crowding relapse.

Keywords: Relapse. Corrective orthodontics. Malocclusion.

Objetivo: o presente estudo avaliou, por meio de uma análise retrospectiva, a estabilidade pós-tratamento do alinhamento dos incisivos anterossuperiores de pacientes submetidos ao tratamento ortodôntico sem extrações. Métodos: a amostra foi constituída de 23 pacientes (13 do sexo feminino e 10 do sexo masculino), com idade inicial de $13,36 \pm 1,81$ anos. Mediu-se nos modelos de estudo das fases inicial $\left(\mathrm{T}_{1}\right)$, final $\left(\mathrm{T}_{2}\right)$ e pós-tratamento $\left(\mathrm{T}_{3}\right)$ de aproximadamente de 5 anos, a irregularidade dos incisivos superiores, as distâncias intercaninos e entre os primeiros e segundos pré-molares, a distância intermolares, o comprimento e o perímetro da arcada superior. Após a obtenção dos dados, realizou-se a análise estatística. Para a análise das alterações ao longo dos três tempos estudados, utilizou-se a análise de variância (ANOVA) a um critério de seleção e, em caso de resultado significativo, o teste de Tukey. Para verificar a presença de correlação entre a recidiva do apinhamento anterossuperior e a recidiva das variáveis distâncias intercaninos, interpré-molares, intermolares, comprimento e perímetro da arcada, utilizou-se o teste de correlação de Pearson. Resultados: os resultados não evidenciaram alterações dimensionais significativas ao final do tratamento; entretanto, durante o período de pós-tratamento, foram observadas alterações significativas em relação à quantidade de irregularidade dos incisivos superiores. Conclusão: concluiu-se que houve recidiva estatisticamente significativa $(+1,52 \mathrm{~mm}) \mathrm{na}$ irregularidade anterossuperior durante o período de pós-tratamento. Entretanto, nenhuma das variáveis aferidas nos modelos pôde ser clinicamente associada à recidiva anterossuperior.

Palavras-chave: Recidiva. Ortodontia corretiva. Má oclusão.

${ }^{1}$ Post-Doctor in Orthodontics, FOB-USP. Professor, Specialization Course in Orthodontics, ABO-PE and FACSETE.

${ }^{2}$ Professor, Orthodontics, FOB-USP.

${ }^{3} \mathrm{PhD}$ in Orthodontics, FOB-USP. Post-Doctor in Orthodontics, Toronto Dentistry University.

${ }^{4}$ Adjunct Professor, Uningá. Professor, Specialization Course in Orthodontics, UFVJM.

${ }^{5}$ Professor, Specialization Course in Orthodontics, UFVJM.
How to cite this article: Canuto LFG, Freitas MR, Freitas KMS, Cançado RH, Neves LS. Long-term stability of maxillary anterior alignment in non-extraction cases. Dental Press J Orthod. 2013 May-June;18(3):46-53.

Submitted: August 12, 2009 - Revised and accepted: December 17, 2010

» The authors report no commercial, proprietary or financial interest in the products or companies described in this article.

Contact address: Luiz Filiphe Gonçalves Canuto

Alameda Octávio Pinheiro Brisolla, 9-75

CEP: 17.012-901 - Bauru/SP - Brazil

E-mail: luizfiliphecanuto@yahoo.com.br 


\section{INTRODUCTION}

The primary purpose of orthodontic treatments is malocclusion correction; however, treatment stability shows considerable variability during post-retention phase. Despite the literature consensus that some occlusal changes will inevitably occur after orthodontic treatment, ${ }^{15,19,28}$ it is noted that long-term stability of the aligned teeth is highly variable and unpredictable. ${ }^{17}$

Greater research emphasis has been placed on relapse of mandibular anterior crowding and little emphasis has been given to investigating the maxillary crowding relapse and parameters that may be helpful in predicting its long-term stability. . $3,3,9,12,18,23,25^{2}$

Alignment stability of mandibular incisors is less than that of the maxillary anterior teeth. ${ }^{8,10,22,26,29,30}$ Factors such as pretreatment crowding severity ${ }^{25}$ and gingival fibers traction ${ }^{5,6,7}$ are considered risk factors for maxillary incisors crowding relapse. However, there is an association between a prolonged period of retention and greater stability of maxillary teeth alignment. ${ }^{23}$ Maxillary incisors tend to rotate in the direction of their initial positions, ${ }^{25,26}$ despite buccolingual relapse being unpredictable. ${ }^{25}$ Furthermore, palatal contacts between maxillary and mandibular incisors preclude lingual movement of the maxillary teeth and any vestibular movement is probably determined by the lips position and function. ${ }^{12}$

Accordingly to Little, ${ }^{14}$ evidence of progressive instability is often first noted by progressive crowding of mandibular incisors following removal of retaining devices. Whatever the multiplicity of causes for relapse, mandibular incisor irregularity is often the precursor of maxillary crowding, deepening of the overbite, and generalized deterioration of orthodontic treated cases.

Kahl-Nieke, Fischbach and Schwarze, ${ }^{13}$ evaluated pretreatment, posttreatment, and post-retention models of 226 cases with all types of anomaly. Findings indicated that relapse of incisors crowding occurred in approximately half of the sample and that post-retention crowding increased more frequently in mandible than in the maxilla. Pretreatment variables such as severe crowding and incisors irregularity, arch length deficiency, arch constriction and increased overbite were found to be associated factors in the process of post-retention increase of crowding and incisors irregularity. Premolars extraction treat- ment exhibited greater maxillary and mandibular crowding relapse than non-extraction protocol.

In a longitudinal study, Moussa, O'Reilly and Close, ${ }^{18}$ evaluated 55 non-extraction orthodontic patients that were previously submitted to rapid palatal expansion (RPE). The authors ${ }^{18}$ observed that maxillary incisors irregularity increased $0.60 \mathrm{~mm}$ during post-retention. They suggested that RPE procedure may be helpful in long-term stability; however, due to the absence of a control group there was no clear evidence about a possible influence of RPE procedure on the crowding relapse. However, Canuto et al, ${ }^{3}$ compared the long-term stability of maxillary incisor alignment in patients treated with and without rapid maxillary expansion. They concluded that RME did not influence long-term maxillary anterior alignment stability.

Vaden, Harris and Gardner, ${ }^{30}$ concluded that most (96\%) of the maxillary incisor irregularity correction was maintained after 15 years of treatment. At the post-retention recall, the maxillary irregularity index increased only $0.30 \mathrm{~mm}$. Surbeck et $\mathrm{al}^{25}$ evaluated whether pretreatment misalignment of the maxillary anterior teeth are of significance for post-retention relapse of alignment. The results suggested that anatomic contact point displacement of the maxillary anterior teeth and maxillary incisor rotation relative to the dental arch are significant risk factors for postretention relapse of alignment and that the pattern of rotational displacement relative to the dental arch has a strong tendency to repeat itself.

Taner et $\mathrm{al}^{27}$ evaluated the effects of fiberotomy in alleviating dental relapse of incisors after orthodontic treatment. The authors described that there was significant increase of irregularity index in the control group, for both maxillary and mandibular anterior segments. Meanwhile, in the group where circumferential supracrestal fiberotomy was performed, no significant increase of the irregularity index was noted. One year later, Huang and Artun, ${ }^{12}$ evaluated whether post-retention relapse of maxillary and mandibular incisor alignment were associated. The authors suggested ${ }^{12}$ that the occlusal contacts with the mandibular anterior teeth represent lingual boundaries for the maxillary incisor movement, and any labial movement is likely to be determined by the position and function of the lips. In addition, also suggested 
that the post-retention movement of the mandibular incisors may be influenced by the position of the maxillary incisors and vice versa and indicated that an association between the post-retention misalignment of the incisors in the 2 arches might exist.

Ferris et $\mathrm{al}^{9}$ investigated the long-term post-retention stability of RPE-lip bumper therapy followed by full fixed appliances. The sample comprised $20 \mathrm{pa}-$ tients at the late mixed dentition that were recalled to obtain post-retention records. The subjects were out of retention for an average of 7.9 years. The majority of treatment increases in maxillary and mandibular arch dimensions were maintained during post-retention phase. Post-retention incisor irregularity increased $0.5 \mathrm{~mm}$ in the maxillary arch and $1.1 \mathrm{~mm}$ in the mandibular arch. The authors ${ }^{9}$ concluded that use of RPE-lip bumper therapy in the late mixed dentition followed by full fixed appliances is an effective form of treatment for patients with up to moderate tooth size-arch length discrepancies.

Erdinc, Nanda and Isiksal, ${ }^{8}$ evaluated long-term stability of incisor crowding in orthodontic patients treated with and without premolar extractions. Minimal incisor crowding relapse occurred $(0.19 \mathrm{~mm}$ and $0.12 \mathrm{~mm}$ for extraction and non-extraction groups, respectively). Maxillary incisor irregularity relapse was smaller than mandibular incisor relapse for both groups. Intercanine width expanded during treatment. Incisor positions in both groups tended to return to pretreatment values. Clinically acceptable stability was obtained. ${ }^{8}$

Because of insufficient studies on maxillary anterior tooth alignment and parameters that may be helpful in predicting its long-term stability, this study aimed to evaluate the long-term maxillary incisors crowding relapse and possible factors that may influence tooth alignment stability.

\section{MATERIAL AND METHODS \\ Material}

The sample was obtained from the files of Bauru Dental School, University of São Paulo, Bauru, São Paulo, Brazil, and consisted of Class I and II malocclusion patients treated orthodontically without extractions.

The criteria for sample selection included the presence of all permanent teeth at treatment beginning (at least first permanent molars) and the absence of shape and/or number dental anomalies. All patients had complete orthodontic records, including study models of the initial phase $\left(T_{1}\right)$, end of treatment $\left(T_{2}\right)$ and post-retention $\left(\mathrm{T}_{3}\right)$. None of the subjects underwent rapid maxillary expansion.

Sample comprised 69 dental casts of 23 subjects (13 girls and 10 boys; initial mean age: 13.36 years; $\mathrm{SD}=1.81$ years) who received full maxillary and mandibular fixed edgewise appliances. These patients underwent orthodontic treatment for a mean period of 2.18 years $(\mathrm{SD}=0.93)$ and were satisfactorily finished at a mean age of 15.54 years $(\mathrm{SD}=1.86)$. The post-retention study models were taken after a mean period of 4.92 years $(\mathrm{SD}=1.11)$.

Regarding initial malocclusion, ten patients had Class I, 8 had quarter-cusp Class II, and 5 had half Class II anteroposterior molar relationships. None of the patients exhibited posterior crossbite at $\mathrm{T}_{1}$.

After active treatment, all patients wore a full time Hawley retainer in the maxillary arch for 12 months. A lingual canine-to-canine mandibular bonded retainer was placed and left for a mean period of 3 years.

\section{Methods}

\section{Dental cast measurements}

The $\mathrm{T}_{1}, \mathrm{~T}_{2}$ and $\mathrm{T}_{3}$ maxillary dental casts were used. All dental cast measurements were made with a centesimal precision digital caliper (Mitutoyo America, Aurora, Ill, São Paulo, Brazil).

All were linear measurements, in millimeters, described as follows:

A) Maxillary incisor irregularity ${ }^{14}$ (LITTLE) (Fig 1).

B) Intercanine width (A; INTERC): The linear distance between the cusp tips of the maxillary canines. When there was a facet, the cusp tip was estimated (Fig 2).

C) Inter-premolar widths (INTERPB and INTERPB'): The linear distance between left and right central fossae of the maxillary first (B) and second (B') premolars (Fig 2).

D) Intermolar width (C; INTERMOL): The linear distance between the mesiobuccal cusps tips of the maxillary first molars. When there was a facet, the cusp tip was estimated (Fig 2).

E) Arch length (D + E; LENGTH): The linear distance along the midline from the interincisal midline to the mesial contact of the first molars (Fig 2). 


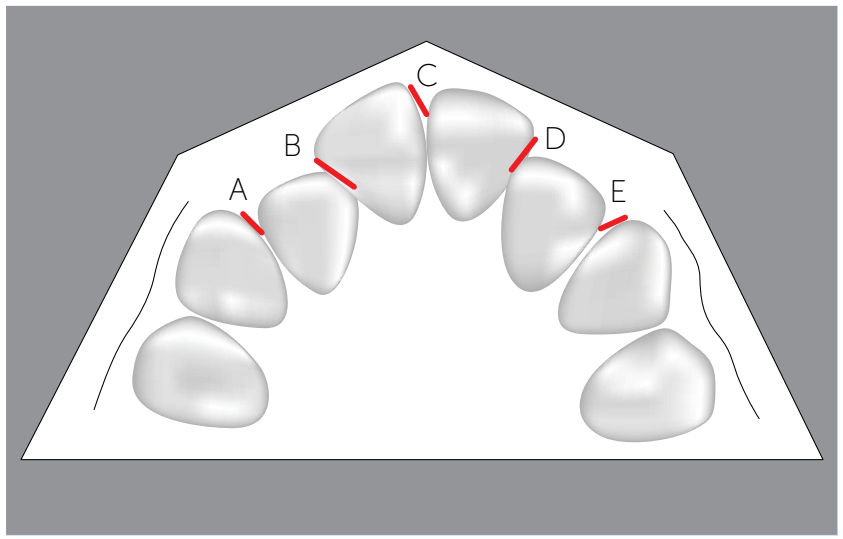

Figure 1 - Little Irregularity Index (modified for the upper arch) $=A+B+C+D+E$.

F) Arch perimeter (F; PERIM): The distance in millimeters from the mesial dental contact of the left first molars to the mesial dental contact of the right first molars to (Fig 2).

\section{Statistical analysis}

\section{Method error}

Within a month interval from the first measurement, ten dental casts from $\mathrm{T}_{1}, \mathrm{~T}_{2}$ and $\mathrm{T}_{3}$ phases were randomly selected and remeasured. The casual error was calculated according to Dahlberg's formula $\left(\mathrm{Se}^{2}=\Sigma \mathrm{d}^{2} / 2 \mathrm{n}\right) .{ }^{4}$ The systematic error was calculated with dependent $t$ tests, according to Houston. ${ }^{11}$

\section{Statistical method}

One-way dependent ANOVA and Tukey tests were used to evaluate the behavior of the measured variables during the three phases (Initial $-\mathrm{T}_{1}$; Posttreatment $-\mathrm{T}_{2}$; Post-retention $-\mathrm{T}_{3}$ ).

The Pearson correlation coefficient was calculated by using the whole sample to investigate a significant correlation between maxillary incisors crowding relapse and the pretreatment irregularity or the amount of crowding correction.

Pearson correlation coefficient was also calculated to investigate a association between maxillary incisors crowding relapse and the relapse of intercanine, interpremolar or intermolar widths, arch length and perimeter.

The results were considered statistically significant at $\mathrm{p}<0.05$. All statistical analyses were performed with the software Statistica for Windows, version 6.0, Statsoft, Tulsa, Okla, USA.

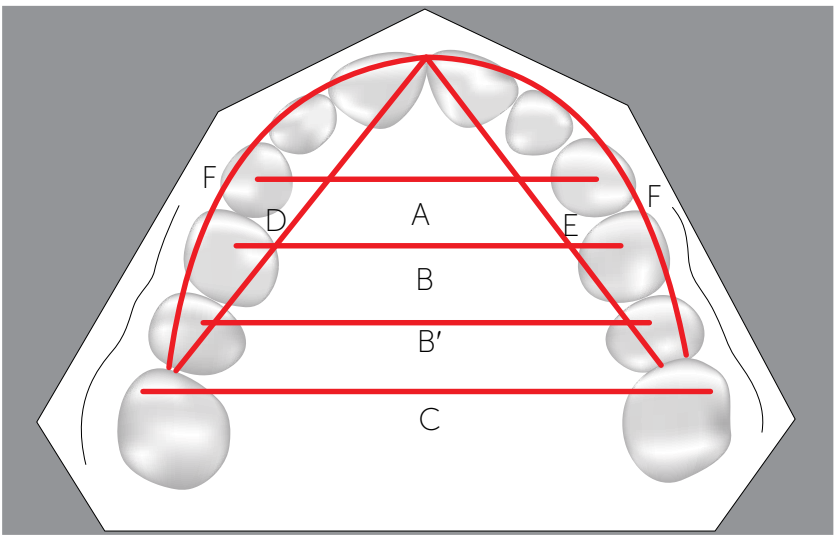

Figure 2 - Variables studied on dental casts: A, intercanine width; B, inter-firstpremolar width; B', inter-second-premolar width; C, intermolar width; D + E, arch length; F, arch perimeter.

\section{RESULTS}

Dahlberg's formula and Paired t tests showed no significant casual and systematic errors.

The Table 1 exhibits results of one-way analysis of variance (ANOVA) with the post-hoc Tukey test (different letters means a statistically significant difference between variables) that were used to determine whether there was a significant difference between the measured variables during $\mathrm{T}_{1}, \mathrm{~T}_{2}$ and $\mathrm{T}_{3}$. The results showed that the incisors irregularity had significant changes not only during treatment but also at posttreatment. Maxillary crowding relapse occurred in most patients with a mean percentage of $30.64 \%$ of the treatment correction. However, no significant differences were detected to the dimensional variables evaluated during the 3 phases, except for the inter-first-premolar width (INTERPB), that exhibited a statistically significant increase from pretreatment $\left(\mathrm{T}_{1}\right)$ to posttreatment $\left(\mathrm{T}_{2}\right)$.

Results of the Pearson correlation tests are in the Tables 2 and 3. There was a significant and negative correlation between maxillary incisors crowding relapse and the relapse of the intercanine and interfirst-premolar widths.

\section{DISCUSSION}

Although incisors alignment relapse in maxillary arch is less prevalent than in mandibular arch, the evaluation of possible factors that may influence maxillary tooth alignment stability has validity. Relapse of crowding in this region may also results in esthetic and functional occlusal deficiencies. Mainly due to its 
Table 1 - Results of one-way analysis of variance (ANOVA) with the post-hoc Tukey test (different letters means a statistically significant difference between variables) for the variables measured on dental casts $(N=23)$, at the three stages studied $\left(T_{1}, T_{2}\right.$ and $\left.T_{3}\right)$.

\begin{tabular}{|c|c|c|c|c|}
\hline Variable & Initial $\left(T_{1}\right)$ & Posttreatment $\left(\mathrm{T}_{2}\right)$ & Post-retention $\left(\mathrm{T}_{3}\right)$ & $\mathbf{p}$ \\
\hline & Mean \pm SD & Mean \pm SD & Mean \pm SD & \\
\hline LITTLE & $6.56 \pm 2.83^{A}$ & $1.59 \pm 0.73^{8}$ & $3.11 \pm 1.41^{c}$ & $0.000 *$ \\
\hline INTERC & $34.07 \pm 3.79^{A}$ & $34.65 \pm 1.44^{\mathrm{A}}$ & $34.53 \pm 1.87^{A}$ & 0.653 \\
\hline INTERPB & $34.71 \pm 1.86^{A}$ & $36.34 \pm 1.81^{B}$ & $35.76 \pm 1.81^{B}$ & $0.012^{\star}$ \\
\hline INTERPB' & $40.20 \pm 2.31^{A}$ & $41.35 \pm 2.15^{A}$ & $41.09 \pm 2.16^{A}$ & 0.186 \\
\hline INTERMOL & $51.13 \pm 2.62^{A}$ & $51.52 \pm 2.50^{A}$ & $51.94 \pm 2.51^{\mathrm{A}}$ & 0.560 \\
\hline LENGTH & $72.09 \pm 4.08^{A}$ & $73.76 \pm 2.49^{A}$ & $72.07 \pm 2.58^{A}$ & 0.118 \\
\hline PERIM & $75.18 \pm 3.77^{A}$ & $76.52 \pm 2.66^{A}$ & $75.32 \pm 2.55^{A}$ & 0.269 \\
\hline LITTLE & $6.56 \pm 2.83^{A}$ & $1.59 \pm 0.73^{B}$ & $3.11 \pm 1.41^{c}$ & $0.000 *$ \\
\hline
\end{tabular}

Table 2 - Results of the Pearson correlation test

\begin{tabular}{ccc}
\hline Variable & r & $p$ \\
\hline LITTLE1 x LITTLE3 & 0.252 & 0.071 \\
LITTLE1 x LITTLE3-2 & 0.241 & 0.084 \\
LITTLE2-1 x LITTLE3-2 & -0.264 & 0.055 \\
\hline
\end{tabular}

location, maxillary incisors crowding relapse tends to become more visible and therefore promote greater esthetic impacts than mandibular irregularity.

Results for one-way analysis of variance (ANOVA) with the post-hoc Tukey test (Table 1) showed that occurred statistically significant changes in the Little irregularity index during the three phases studied. It was observed a significant maxillary crowding reduction during treatment. However, there was a significant relapse of the incisors irregularity after treatment. Regarding changes in maxillary arch dimensions during treatment, there was only a significant change in the variable INTERPB (Inter-first-premolar width), suggesting that most maxillary arch dimensions were maintained during treatment, and remained stable during post-retention. Sadowsky et $\mathrm{al}^{23}$ evaluating stability in maxillary and mandibular dental arches of patients treated without extractions and Edgewise mechanics, observed no significant changes in the intercanine and inter-premolars widths, five years post-retention. Erdinc, Nanda and Isiksal, ${ }^{8}$ evaluated stability of the orthodontic treatment, with and without extractions. Similarly to the present study, it was
Table 3 - Results of the Pearson correlation test.

\begin{tabular}{ccc}
\hline Variable & $r$ & $p$ \\
\hline LITTLE3-2 $\times$ INTERC3-2 & -0.459 & $0.000^{*}$ \\
\hline LITTLE3-2 $\times$ INTERPB3-2 & -0.419 & $0.001^{*}$ \\
\hline LITTLE3-2 $\times$ INTERPB'3-2 & -0.269 & 0.053 \\
\hline LITTLE3-2 $\times$ INTERMOL3-2 & -0.064 & -0.649 \\
\hline LITTLE3-2 $\times$ LENGTH3-2 & 0.028 & 0.842 \\
\hline LITTLE3-2 $\times$ PERIM3-2 & -0.012 & 0.930 \\
\hline
\end{tabular}

*Statistically significant at $p<0.05$.

observed significant decreases in maxillary incisors irregularity during treatment. Patients treated without extractions exhibited significant increases of the intercanine and inter-premolars widths during treatment. The maxillary arch dimensional measurements showed no significant changes after treatment, however, relapse of maxillary crowding was significant. These studies ${ }^{8,23}$ and the present suggests a favorable prognosis regarding maxillary arch long-term dimensional stability of orthodontic cases treated without premolars extractions.

In the present study, mean post-retention crowding relapse was $1.52 \mathrm{~mm}$. Sadowsky et al, ${ }^{23}$ assessing stability of subjects treated non-extraction, reported a relatively similar amount of relapse $(1.1 \mathrm{~mm})$, 5 years post-retention. However, Moussa, O’Reilly and $\mathrm{Close}^{18}$ observed more favorable results regarding crowding relapse, 8 to 10 years post-retention, in a sample comprising 18 subjects treated with rapid maxillary expansion and fixed appliances. It was observed a mean maxillary crowding relapse of $0.6 \mathrm{~mm}$ $(\mathrm{SD}=1.30)$. Vaden, Harris and Gardner, ${ }^{30}$ noted that $96 \%$ of the maxillary crowding correction remained 
stable 15 years after treatment. The amount of crowding increased from $1.5 \mathrm{~mm}$ at posttreatment to 1.8 $\mathrm{mm}$ at post-retention. Ferris et $\mathrm{al}^{9}$ also evaluated the maxillary crowding relapse in non-extraction cases. It was observed only $0.47(\mathrm{SD}=1.19)$ of maxillary irregularity increase during the post-retention (7.9 years). The increased stability observed in these studies may be explained by the prolonged retention protocol after orthodontic treatment. ${ }^{23}$ In the Sadowsky et $\mathrm{a}^{23}$ study, retainers were placed and left for a mean period of 8.4 years. Moussa, O'Reilly and Close, ${ }^{18}$ described a mean period of 6.6 years of retention for the mandibular arch and full time Hawley retainer in the maxillary arch for 2 years. The study conducted by Vaden, Harris and Gardner, ${ }^{30}$ reports that patients used these retainers in the maxillary and mandibular arches or these retainers in the maxillary arch and a lingual canine-to-canine mandibular bonded retainer. The first posttreatment control was carried out only after six years. The study by Ferris et $\mathrm{al}^{9}$ described a retention protocol that included the use of Hawley in the maxillary for 3 years (full time during one year) and lingual bonded retainer or Hawley plates in the mandibular arch for a mean period of 3 years. In the present study, all subjects wore a full time Hawley retainer in the maxillary arch for 12 months. A lingual canine-to-canine mandibular bonded retainer was placed and left for a mean period of 3 years.

Erdinc, Nanda and Isiksal ${ }^{8}$ described an increase in maxillary incisors irregularity of $0.19 \mathrm{~mm}$ and $0.12 \mathrm{~mm}$ for patients treated with or without extractions, respectively, 4 years and 11 months after treatment. The extraction group showed $4.4 \mathrm{~mm}$ of pretreatment crowding. However, the non-extraction group exhibited only $1.94 \mathrm{~mm}$ of initial irregularity. The initial crowding was significantly less severe than that observed in our sample $(6.56 \mathrm{~mm})$. Maxillary and mandibular retainers were removed at least two years before the post-retention measurements. The exceptional stability of this study may be related to the amount of initial crowding and due to a short interval between retainer removal and the postretention evaluation.

Although the results indicate a posttreatment maxillary crowding relapse greater than that reported in previous studies, ${ }^{8,9,18,23,30}$ the mean irregularity index at posttreatment $(3.12 \mathrm{~mm})$ is considered clinically acceptable according to Little. ${ }^{14}$
Results of the Pearson correlation tests showed no significant correlations to most variables evaluated (Tables 2 and 3). It was observed that the amount of initial crowding had no effect on relapse, as described in previous studies. ${ }^{1,17}$ Surbeck et al,,$^{25}$ in contrast, reported a positive correlation between the amount of maxillary incisors irregularity and the amount of incisors crowding relapse. The authors reported ${ }^{25}$ that the tendency to maxillary crowding relapse increases 2.3 times for each $0.2 \mathrm{~mm}$ of incisors contact point displacement in relation to the dental arch. Furthermore, each $4^{\circ}$ of tooth rotation at pretreatment has increased by 2.7 times the probability of irregularity relapse. The authors ${ }^{25}$ also pointed out that partially aligned tooth exhibits significant risk of relapse. They suggested the use of individualized retention protocols and that patients should be aware about the possibility of relapse accordingly to the initial irregularity. ${ }^{25}$ However, a positive correlation between the amount maxillary incisors crowding at pretreatment and the crowding relapse after treatment seems unlikely when analyzing our results and previous studies. For example, ours results indicated that the experimental group exhibited $6.56 \mathrm{~mm}$ of initial irregularity and had a mean post-retention relapse of $1.52 \mathrm{~mm}$. The mean crowding relapse observed in the present study was higher than that reported by Ferris et al, ${ }^{9}$ Sadowsky et $\mathrm{al}^{23}$ and Vaden, Harris and Gardner, ${ }^{30}$ with samples that exhibited more maxillary incisors irregularity at pretreatment $(10.45 \mathrm{~mm}, 8.0 \mathrm{~mm}$ and $7.9 \mathrm{~mm}$, respectively). Despite more initial crowding, these studies reported less posttreatment irregularity relapse $(0.47 \mathrm{~mm}, 1.1 \mathrm{~mm}, 0.3 \mathrm{~mm}$, respectively).

The amount of maxillary crowding relapse (LITTLE3-2) showed a statistically significant and negative correlation $(p<0.05)$ with the post-retention changes in intercanine (INTERC3-2) and inter-first-premolars (INTERPB3 -2) widths (Table 3). These results suggest that the higher the post-retention decreases of intercanine and inter-first-premolars widths the higher the maxillary crowding relapse. However, although these correlations have statistical significance, the coefficients values observed implicate in a weak correlation ( $r$ values of -0.459 and -0.419 , respectively). Therefore, it can be argued that the observed correlation between relapse of the maxillary crowding and the reduction of these dimensional measurements has poor clinical significance. 
Moreover, it seems obvious that the reduction of these measurements tends to be consequence of maxillary arch constriction in the anterior region. Therefore, it is expected a space availability decrease and an increase in the amount of tooth crowding.

Despite numerous studies that evaluated a possible relationship between changes in intercanine width and mandibular incisors crowding relapse, the correlation between maxillary crowding relapse and maxillary intercanine width changes were only investigated by Surbeck et $a 1,{ }^{25}$ and Erdinc, Nanda and Isiksal. ${ }^{8}$ Surbeck et $\mathrm{al}^{25}$ found a significant association ( $\left.\mathrm{p}<0.001\right)$ between intercanine width decreases and maxillary incisors crowding relapse, however, the correlation test result also revealed a weak association $(r<0.70)$. Erdinc, Nanda and Isiksal, ${ }^{8}$ found no correlation between post-retention changes in incisors irregularity and changes in intercanine width.

\section{Clinical implications}

Maxillary anterior alignment shows better prognosis regarding stability when compared to the same region in the mandibular arch, this fact may explain the scarce studies in literature about this issue. Despite the greater stability, maxillary crowding relapse can compromise orthodontic results after retention appliances removal. The post-retention relapse observed in this study $(1.52 \mathrm{~mm})$, although statistically significant, may be considered clinically acceptable. ${ }^{14}$ Otherwise, this minimal amount of crowding relapse can lead to patient dissatisfaction.

Maxillary incisors crowding relapse shows some etiological factors as retention time, initial crowding severity; relapse of teeth in the opposite side, changes in arch dimensions, rotated teeth at pretreatment and lack of complete correction of rotated teeth resulting in absence of adequate interdental contacts. Thus, it becomes clear that more stable results can be obtained with a prolonged retention protocol and an adequate alignment of maxillary incisors during treatment.

\section{CONCLUSION}

The maxillary incisors irregularity increased significantly $(1.52 \mathrm{~mm})$ five years posttreatment.

None of the clinical factors studied in the dental casts demonstrated to be predictive of the maxillary crowding relapse.

The results suggest that more attention regarding maxillary arch retention protocol should be taken by the clinician. Although alignment stability of mandibular incisors is less than that of the maxillary anterior teeth, maxillary crowding relapse can be significant. 


\section{REFERENCES}

1. Artun J, Garol JD, Little RM. Long-term stability of mandibular incisors following successful treatment of Class II, Division 1, malocclusions. Angle Orthod. 1996:66(3):229-38

2. Busdrang PH, Horton-Reuland SJ, Legler L, Nevant C. Non-extraction approach to tooth size arch length discrepancies with the Alexander discipline. Semin Orthod. 2001;7(2):117-31.

3. Canuto LF, Freitas MR, Janson G, Freitas KM, Martins PP. Influence of rapid palatal expansion on maxillary incisors alignment stability. Am J Orthod Dentofacial Orthop. 2010;137(2):164.e1-6.

4. Dahlberg G. Statistical methods for medical and biological students. New York: Interscience; 1940

5. Edwards JG. A study of the periodontium during orthodontic rotation of teeth. Am J Orthod. 1968;54(6):441-61.

6. Edwards JG. A surgical procedure to eliminate rotational relapse. Am J Orthod. 1970;57(1):35-46

7. Edwards JG. A long-term prospective evaluation of the circumferential supracrestal fiberotomy in alleviating orthodontic relapse. Am J Orthod Dentofacial Orthop. 1988:93(5):380-7.

8. Erdinc AE, Nanda RS, Işiksal E. Relapse of anterior crowding in patients treated with extraction and non-extraction of premolars. Am J Orthod Dentofacial Orthop. 2006:129(6):775-84.

9. Ferris T, Alexander RG, Boley J, Buschang PH. Long-term stability of combined rapid palatal expansion-lip bumper therapy followed by full fixed appliances. Am J Orthod Dentofacial Orthop. 2005:128(3):310-25.

10. Heiser W, Niederwanger A, Bancher B, Bittermann G, Neunteufel N, Kulmer S. Three-dimensional dental arch and palatal form changes after extraction and non-extraction treatment. Part 1. Arch length and area. Am J Orthod Dentofacial Orthop. 2004;126(1):82-90.

11. Houston WJ. The analysis of errors in orthodontic measurements. Am J Orthod. 1983:83(5):382-90

12. Huang L, Artun J. Is the post-retention relapse of maxillary and mandibular incisor alignment related? Am J Orthod Dentofacial Orthop. 2001:120(1):9-19

13. Kahl-Nieke B, Fischbach H, Schwarze CW. Post-retention crowding and incisor irregularity: a long-term follow-up evaluation of stability and relapse. Br J Orthod. 1995:22(3):249-57.

14. Little RM. The irregularity index: a quantitative score of mandibular anterior alignment. Am J Orthod. 1975:68(5):554-63.

15. Little RM. Stability and relapse of dental arch alignment. Br J Orthod 1990:17(3):235-41.
16. Little RM, Riedel RA, Artun J. An evaluation of changes in mandibular anterior alignment from 10 to 20 years post-retention. Am J Orthod Dentofacial Orthop. 1988;93(5):423-8

17. Little RM, Wallen TR, Riedel RA. Stability and relapse of mandibular anterior alignment - first premolar extraction cases treated by traditional edgewise orthodontics. Am J Orthod. 1981;80(4):349-65.

18. Moussa R, O'Reilly MT, Close JM. Long-term stability of rapid palatal expander treatment and edgewise mechanotherapy. Am J Orthod Dentofacial Orthop. 1995:108(5):478-88

19. Parker WS. Retention: retainers may be forever. Am J Orthod Dentofacial Orthop. 1989;95(6):505-13.

20. Richardson ME. A review of changes in lower arch alignment from seven to fifty years. Semin Orthod. 1999:5(3):151-9.

21. Rossouw PE, Preston CB, Lombard CJ, Truter JW. A longitudinal evaluation of the anterior border of the dentition. Am J Orthod Dentofacial Orthop. 1993:104(2):146-52.

22. Sadowsky C, Sakols El. Long-term assessment of orthodontic relapse. Am J Orthod. 1982;82(6):456-63.

23. Sadowsky C, Schneider BJ, BeGole EA, Tahir E. Long-term stability after orthodontic treatment: non-extraction with prolonged retention. Am J Orthod Dentofacial Orthop. 1994:106(3):243-9

24. Sinclair PM, Little RM. Maturation of untreated normal occlusions. Am J Orthod. 1983;83(2):114-23

25. Surbeck BT, Artun J, Hawkins NR, Leroux B. Associations between initial, posttreatment, and post-retention alignment of maxillary anterior teeth. Am J Orthod Dentofacial Orthop. 1998:113(2):186-95.

26. Swanson WD, Riedel RA, Danna JA. Post-retention study: incidence and stability of rotated teeth in humans. Angle Orthod. 1975;45(3):198-203.

27. Taner TU, Haydar B, Kavuklu I, Korkmaz A. Short-term effects of fiberotomy on relapse of anterior crowding. Am J Orthod Dentofacial Orthop. 2000:118(6):617-23.

28. Thilander B. Orthodontic relapse versus natural development. Am J Orthod Dentofacial Orthop. 2000;117(5):562-3.

29. Unde MD, Sadowsky C, BeGole EA. Long-term stability of dental relationships after orthodontic treatment. Angle Orthod. 1983:53(3):240-52.

30. Vaden JL, Harris EF, Gardner RL. Relapse revisited. Am J Orthod Dentofacial Orthop. 1997:111(5):543-53. 